NASA Technical Memúrandưum 89889

AIAA-87-9003

\title{
Space Station Electric Power System Requirements and Design
}

\author{
(HASA-TM-89889) SPACE STATICY ELECTRIC \\ FCEER SYSTEL FECUIREEEATS ABD LESIGN (NASA) \\ $15 \mathrm{P}$ Avail: NIS HC AO2/AF 101 CSCL 22B
}

N87-22001

Fred Teren

Lewis Research Center

Cleveland, Ohio

\section{Prepared for the}

22nd Intersociety Energy Conversion Engineering Conference cosponsored by the AIAA, ANS, ASME, SAE, IEEE, ACS, and AIChE Philadelphia, Pennsylvania, August 10-14, 1987

\section{N/SA}


Fred Teren*

National Aeronautics and Space Administration

Lewis Research Center

Cleveland, ohio 44135

\section{Abstract}

This paper gives an overview of the conceptual definition and design of the Space Station electric power system (EPS). Responsibilities for design and development of the EPS are defined. The EPS requirements are listed and discussed, including average and peak power requirements, contingency requirements, and fault tolerance. The most significant Phase $B$ trade study results are summarized, and the design selections and rationale are given. Finally, the power management and distribution system architecture is presented.

\section{Background}

NASA has been engaged in the definition and design of the Space Station and platforms since 1984. Phase $B$ contracts were awarded by four work package (WP) centers for definition and preliminary design of the Space Station and platforms and their various systems. These contracts were completed early in 1987. NASA plans to award contracts for the design and development of the space Station and platforms in the fall of 1987. The subject of this paper is the requirements for, and design of, the Space Station electrical power system (EPS), as defined at completion of the Phase $B$ effort.

The Space Station EPS is the responsibility of the NASA Lewis Research Center, also known as work package-04 (WP-04) in the Space Station program. WP-04 is responsible for the end-to-end electric power system architectures for the Space Station and platforms, including photovoltaic and solar dynamic power generation and storage, and power management and distribution (PMAD) to the final user interface. This responsibility includes end-to-end system design, and DDTaE and production of all system hardware and software. In addition, WP-04 is responsible for the photovoltaic and solar dynamic power module elements. This element responsibllity includes DDTDE, production of unique element hardware, and installation and checkout of all hardware into the modules. WP-O4 is also responsible for the integration of the solar dynamic power module into the NSTS for launch. The photovoltaic power module and PMAD hardware are packaged and delivered to the appropriate site for integration. For the platforms, ORU and/or component level hardware are delivered to WP-03 for installation and integration into the platform element.

\section{Requirements}

The major EPS requirements are as follows. The EPS is required to have the capability to deliver $87.5 \mathrm{~kW}$ of electric power continuously to the user loads. In addition, the EPS must be able to deliver up to $112.5 \mathrm{~kW}$ of peak power for up to $15 \mathrm{~min}$ each orbit. Since the power system operates in low earth orbit (LEO), there is a significant amount of shade

*Associate Fellow, AIAA. time when the Station passes through the Earth's shadow during each orbit. As a result, a large amount of energy storage capacity is required, in order to provide the $87.5 \mathrm{~kW}$ of power continuously during periods of shade as well as sunlight. Furthermore, as a result of the LEO operating regime, the aerodynamic drag force resulting from solar collecting surfaces is a major driving requirement. other requirements which represent significant design drivers for the EPS are as follows:

(1) A minimum level of power must be available during contingency periods, such as when control has been lost and the EPS cannot be pointed at the sun.

(2) Critical loads, requiring two-faulttolerant electrical power, may be located anywhere on the Station, efther inside or outside the pressurized modules.

(3) The power system design must be capable of accommodating later growth to a $300 \mathrm{~kW}$ power level.

(4) The power system must be on-orbit maintainable, through the use of orbital replacement units (ORU).

(5) The Station power system design should minimize IOC cost; in addition, life cycle cost (LCC) is an important factor and should also be kept low.

(6) Low mass is very important for the platform power system.

(7) To minimize cost, maximum commonality between Station and platform PMAD components should be sought.

\section{Design Options and Selections}

The most important design choice for the Space Station EPS was the selection of the power generation and storage system. The possible options are all photovoltaic (PV), all solar dynamic (SD) and hybrid (a combination of PV and SD).

A PV system has solar arrays for power generation, and chemical energy storage (batteries or fuel cells) to store excess solar array energy during perlods of sunlight, and provide power during periods of shade. A PV system is generally characterized by low development cost and high recurring cost (due to maturity of solar array development and high cost of solar cells and panels); low efficiency due to the approximate 10 percent efficiency of solar cells; and high drag from the large solar array panels required to capture sufficient sunight to meet required user power levels.

Solar dynamic systems use solar radiation to heat a working fluid in a closed loop. The fluid does work on a turbine which drives an alternator, converting thermal energy to mechanical to electrical energy. Heat is added to the fluid in a heat receiver which absorbs focused solar radiation from 
a sun-tracking concentrator with a reflective surface. The receiver and concentrator are oversized to allow excess thermal energy to be stored in a melting salt as the heat of fusion when the system is in the sun. During solar eclipse, some of the salt solidifles, releasing heat to the working fluid which continuously powers the turboalternator. Radiators are required by solar dynamic systems to reject the waste cycle heat to space. Solar dynamic systems are characterized by higher development costs (because they have never flown in space before) but lower recurring costs; slower performance degradation due to aging; much higher efficiency than PV systems, and, consequently, much lower drag.

Extensive trade studies were conducted comparing PV, SD, and hybrid EPS options during the Phase $B$ effort. The hybrid option was judged to be superior to either a 11-PV or a 11-SD options, and was selected for development. The following are the major factors which contributed to the selection of the hybrid EPS:

(1) An al1-SD system was ruled out because the Space Station assembly plan requires the Station to fly in a low-drag feathered mode for the first several shuttle launches. The So system requires fine pointing, and will not deliver power when collectors are feathered. In addition, an So system cannot provide contingency power when pointing capability is lost.

(2) An all PV system would have very high life cycle cost, especially when the requirement for growth to $300 \mathrm{~kW}$ is considered. The high life cycle cost results primarily from the high cost of solar arrays, and the high drag and resulting large amount of drag makeup propellant which must be transported from the ground to the space station orbit.

(3) The hybrid PV/SD system offers increased flexiblity over an all-SD system, and gives an overwhelming life cycle cost saving compared to an a 17-PV system. In the selected hybrid power system approach, the first $37.5 \mathrm{~kW}$ of power is supplied by a PV system. This allows power availability for early Station bulldup, even when the arrays are not fine-pointed at the sun. It also provides contingency power if solar pointing is lost for a period of time. The additional $50 \mathrm{~kW}$ of power required by the IOC Space station is supplied by adding two SO power modules, each of which can provide $25 \mathrm{~kW}$ of electric power to the user loads. In addition, all growth power additions will be provided by adding SD power modules. Limiting the amount of PV power to the initial $37.5 \mathrm{~kW}$ allows the space station to achieve the maximum reduction in life cycle cost compared to an a 11 PV system, by minimizing drag and drag makeup propellant, as well as minimizing the recurring cost of additional power modules required for Station growth. The hybrid system can operate at a lower altitude than the all-PV system. This provides significant transportation cost savings for the logistics supply to the Station.

\section{Photovoltaic System Selections}

Having selected a hybrid power system and the power split between PV and SD, the next step is to choose the PV and SO system design. Major design options for the PV solar array included the solar cell material and size, and flexible/deployable versus rigid/erectable arrays. An 8 by $8 \mathrm{~cm}$ Si solar cell was selected. The large cell size minimizes the number of cells and interconnects, and results in lower cost. A flexible, deployable solar array was selected to minimize mass and allow automated array deployment with minimal crew involvement in addition to taking advantage of the high state of technology readiness based on OAST-1.

Figure 1 illustrates the solar array wing concept. Each wing consists of two blanket assemblies tiled with large-area solar cells. These are stowed in their respective blanket boxes. The blanket boxes are, in turn, attached to a deployment canister via a blanket box positioning mechanism. Each pair of blankets is to be deployed and supported by a collable, continuous longeron mast. A tension mechanism is to supply tension to the blanket as it reaches complete extension. The entire wing is tied structurally to the transverse boom by means of the beta gimbal assembly.

$\mathrm{N}_{1}-\mathrm{H}_{2}$ batteries were selected as the energy storage system for both the Space Station and platforms. Other candidate options considered were regenerative $\mathrm{H}_{2}-\mathrm{O}_{2}$ cells and $\mathrm{Ni}$-Cd batteries. The rationale was based upon the $\mathrm{Ni}-\mathrm{H}_{2}$ system being space qualified, although the applications were for geosynchronous orb1t and low voltage (28 V) systems. The $\mathrm{Ni}-\mathrm{H}_{2}$ option also satisfied requirements driven by the polar platform; minimum weight and high reliability with minimum redundancy. The systems level trade studies showed that for Station power levels under $50 \mathrm{~kW}$, a $\mathrm{Ni}-\mathrm{H}_{2}$ battery system using a single cell size offered maximum commonality with platforms and resulted in the lowest development cost and lowest initial operating cost for the program.

A 23-cell pack is used as the building block for energy storage batteries. $\mathrm{Ni}-\mathrm{H}_{2}$ cells in the 40 to $70 \mathrm{~A}-\mathrm{hr}$ range, wiring harness, and mechanical/ thermal support components comprise a pack of the configuration shown in Fig. 2. On discharge, this operates near $28 \mathrm{~V}$. As such, it allows the flexibility to connect several packs in series to obtain a high voltage system for the Station and Platforms or use of single packs as a candidate for other low voltage applications. Packs are arranged in ORU's along with dedicated electronics. All components are mounted to cold plate thermal control surfaces in a design which accommodates the thermal environment of the element in which it is being used.

Photovoltaic power modules are located on the transverse boom, outboard of the truss element alpha gimbals. Each one consists of solar arrays, beta gimbals, radiator panels, a storage and control bay (includes energy storage and thermal control assemblies), and truss members as shown in Fig. 3. The module integrates hardware that serves the electric power system functions of energy collection, storage and conversion, system protection and distribution, and power management and control for the Space Station. A module integrating power system hardware is not defined for the platforms.

\section{Solar Dynamic System Selections}

The most significant SD design choice is between the organic rankine cycle (ORC) and the closed Brayton cycle (CBC) for the thermodynamic 
cycle. The ORC system uses an organic fluid, toluene, for the working fluid which exists in the system in two phases, 1iquid and vapor. An organic fluid was selected because it results in an increase in cycle efficiency over inorganic fluids operating between the same high and low temperatures. The high temperature is limited by the chemical stability of the organic fluid, with a maximum fluid temperature of $755^{\circ} \mathrm{F}$ for the baseline ORC system.

The baseline CBC system uses a single-phase, gas working fluid, which is a mixture of helium and xenon. The working fluid mixture was selected for its desirable thermal-fluid properties. The peak cycle temperature of the CBC system is about $1420^{\circ} \mathrm{F}$, with a net cycle efficiency siightly higher than for the ORC.

Both systems use a highly reliable single shaft arrangement with turbine, alternator rotor, and pump (ORC) or compressor (CBC) directly connected. The alternator for both $C B C$ and $O R C$ is a solid rotor, brushless Rice-Lundell type. The turbalternator is part of the power conversion unit (PCU) which includes the rotating machinery, housings and controls. The PCU also includes a regenerative heat exchanger which recovers energy from the fluid that exists from the turbine and preheats the fluid before it enters the receiver, boosting cycle efficiency.

A parabolic concentrator is used to focus the incoming solar energy into the receiver. An offset parabolic concentrator was selected over a symmetric design because of mass moment of inertia considerations, minimum cost, mass, and blockage. The concentrator is made up of hexagonal panels that are fastened together on-orbit. The concentrator design for ORC and CBC is almost identical, with the ORC concentrator slightly larger to account for the difference in cycle efficiency.

The heat receiver not only heats the working fluid but also stores thermal energy to allow the SO system to provide electrical power during solar eclipse. In the $C B C$ receiver, the fluid tubes are arranged around the circumference of the cylindrical cavity, surrounded by metal rings that are filled with phase change material. The ORC receiver uses heat pipes with internal phase change material canisters. The heat pipes smooth out the flux distribution within the receiver, elminating potential hot spots.

Two concepts are proposed for the heat rejection radiators; heat pipe panels and pumped fluid loop panels. Although both ORC and CBC can accommodate either system, the baseline ORC uses heat pipes and the CBC uses a pumped fluid loop concept providing optimal matching between cycle requirements, mass, cost, and reliability considerations.

Figure 4 shows an exploded view of a solar dynamic module (CBC) and Fig. 5 shows an assembled module $(O R C)$. The systems are very similar in layout, with the receiver and PCU mounted near the transverse boom and the radiator mounted in front of the concentrator, edge-on to the sun. In-depth comparisons have been made, and continue to be made between the ORC and CBC systems. The selection of $O R C$ versus $C B C$ will be made as part of the phase $C / 0$ selection process.
Power Management and Distribution System Selections

The most significant PMAD design decision is the selection of the primary distribution system frequency. Both dc and ac options were considered, and both high frequency (typically $20 \mathrm{kHz}$ ) and low frequency (typically $400 \mathrm{~Hz}$ ) ac options were considered. dc distribution was not selected because it had much higher weight and cost than either of the ac options. This is because: (1) solid state dc switchgear is much heavier and more complex than ac switchgear; (2) ground isolation for payloads requires the use of $\mathrm{dc}-\mathrm{dc}$ converters, which are much heavier and lower in efficiency than transformers, which can be used for isolation in ac systems; (3) if power is distributed at solar array voltage (1.e. $150 \mathrm{Vdc}$ ), the cables are very heavy. On the other hand, if the voltage is stepped up to a higher voltage (typically $440 \mathrm{Vdc}$ ), heavy and inefficient $d c-d c$ converters must be utilized.

The performance of the candidate ac systems was relatively similar and the cholce was difficult. Al1 reactive components (i.e. inductors, capacitors, transformers) are much lighter for the $20 \mathrm{kHz}$ system than for the $400 \mathrm{~Hz}$ system, because the energy storage capacity of a reactive component is proportional to the square of the frequency. As a result, the high frequency system components are lighter and less expensive than the corresponding low frequency components. On the other hand, there is extensive experience with high power, $400 \mathrm{~Hz}$ systems on aircraft, which would tend to minimize the development risk of a $400 \mathrm{~Hz}$ Space Station power distribution system. There is extensive $20 \mathrm{kHz}$ component deve1opment experience, but system development experience has been limited to low power.

The major discriminator between $20 \mathrm{kHz}$ and $400 \mathrm{~Hz}$ was electromagnetic interference (EMI). Space Station experiments are sensitive to conducted and radiated EMI from a $400 \mathrm{~Hz}$ system, including all of the harmonics up to about $10 \mathrm{kHz}$. The weight of shielding and filtering required to reduce the EMI from all of these frequencies to acceptable levels in a $400 \mathrm{~Hz}$ system is prohibitive. The EMI in a $20 \mathrm{kHz}$ system is expected to be a more tractable problem: EMI levels are low to begin with; harmonic content is very low because the $20 \mathrm{kHz}$ resonant system design produces a low distortion sine wave; and users are not sensitive to EMI at $20 \mathrm{kHz}$ and higher frequencies. In addition to EMI considerations. audible noise from a $400 \mathrm{~Hz}$ system may be objectionable to the crew. As a result of these considerations, $20 \mathrm{kHz}$ was selected as the primary distribution frequency.

Other major PMAD decisions included the source of power for the PMAD controllers; and a dedicated PMAD data bus versus use of the Station data management system (DMS) for transmission of PMAD control data. Power must be provided to the PMAD controllers prior to startup or restart of the power system to ensure all switchgear is properly set. This can be accomplished by having small primary or secondary batteries colocated with the controllers, or by use of a low power. low voltage dc control power bus to provide controller power from the ma in PV batteries. The control power bus was selected, based on detalled trade study results to which concluded that this method is the lowest cost and mass solution. 
A dedicated PMAD data bus was selected instead of the use of the DMS. This choice leads to minimum cost of the overall data system. Lower cost network interface hardware and software may be utilized in a dedicated PMAD data bus, because the required data rates are lower than those required for the DMS. Furthermore, a dedicated PMAD data bus greatiy simplifies the process of startup and restart of the power system. With a dedicated PMAD bus, power is first provided to PMAD controllers to allow switchgear to be properly set. Next, the power system is started. Then, power is provided to the DMS. finally, the user and subsystem loads are started. With an integrated PMAD/DMS network, the DMS must be powered up prior to the power system, which greatly increases the cost and complexity of the PMAD control power bus.

\section{Reference PMAD System Architecture}

Figure 6 shows the IOC Station hybrid source architecture. The SD system is regulated to produce $208 \mathrm{~V}, 3$-phase, $1200 \mathrm{~Hz}$ ac power. A frequency changer converts the power to $440 \mathrm{~V}, 1$-phase, $20 \mathrm{kHz}$. The solar arrays are regulated to produce $160 \mathrm{Vdc}$; the use of an array clamp instead of a regulator is an option. The charging of the $\mathrm{Ni}_{1}-\mathrm{H}_{2}$ batteries is controlled by the individual charge and discharge regulators. The main inverters recelve approximately $160 \mathrm{Vdc}$ from the arrays and batteries and convert it to regulated $440 \mathrm{~V}$, 1-phase, $20 \mathrm{kHz}$ ac power. The inverter sizing is such that the transmission of peak power ( 1.3 times average power) requires the full capacity of two inverters. The power is transmitted across the alpha joint by roll rings, which are sized to handle peak power requirements for a $300 \mathrm{~kW}$ growth station $(\sim 400 \mathrm{~kW}$ total).

The distribution of power to the upper and lower station is shown in Fig. 7. A dual ring distribution system is used for both the upper and lower keels. Radial distribution is also an option. There are main bus switching assemblies (MBSA) adjacent to each alpha joint and in-line power distribution and control assemblies (PDCA) at the various load locations.

Figure 8 shows the distribution of power to the modules. Two main distribution cables are provided to each of resource nodes 1 and 2 , and one distribution cable each to resource nodes 3 and 4 . The distribution cabling for the entire station is sized to accommodate a growth power level of $175 \mathrm{~kW}$. In addition to cables to the resource nodes, there is a cable for the attached pressurized payload.

Figure 9 shows the module primary distribution architecture. A total of 10 PDCA's are provided for the US Hab and Lab modules, and two additional POCA's for the nodes. No POCA's are provided for the JEM or ESA modules. Isolation transformers are used at each of the module penetrations; they also step the voltage down to $208 \mathrm{~V}$.

The POCA architecture is shown in Fig. 10. Each PDCA consists of two PDCU's. The POCA's are nearly identical inside and outside the modules; the external PDCA's also include transformers for isolation and stepdown to $208 \mathrm{~V}$. Each PDCU contains about 10 RPC's for connecting to loads with a total capacity of about $18 \mathrm{~kW}$. Each PDCU also contains three primary feeder RBI's and a PDCU controller. The feeder RBI's allow a three-fault-tolerant payload connection with a single PDCA. However, only two-fault tolerance is required for safety critical loads. The PDCU controllers are powered by the main bus, and also by a $150 \mathrm{Vdc}$ control power bus which provides power for startup and restart. The controllers exchange information with other components of the power management control system on a dualredundant dedicated power management data bus.

The power management architecture is shown in Fig. 11. The dual redundant power management data bus runs throughout the Station and connects to each POCA, both outside and inside the modules. The dual redundant power management controllers (PMC) each interface to the DMS at a single point. Dedicated point-to-point data lines cross the alpha joint via roll rings and connect to power source controllers outboard of the alpha joint.

\section{Concluding Remarks}

The overview of the Space station electric power system conceptual design has been presented, including requirements, design options and selections. The design meets a 11 of the requirements, including $87.5 \mathrm{~kW}$ average power, peak and contingency power avallability, and two-fault-tolerant power. Work package 4 (managed by NASA Lewis) is ready to proceed with Phase $C / D$, the final design and development of the Space Station electric power system. 


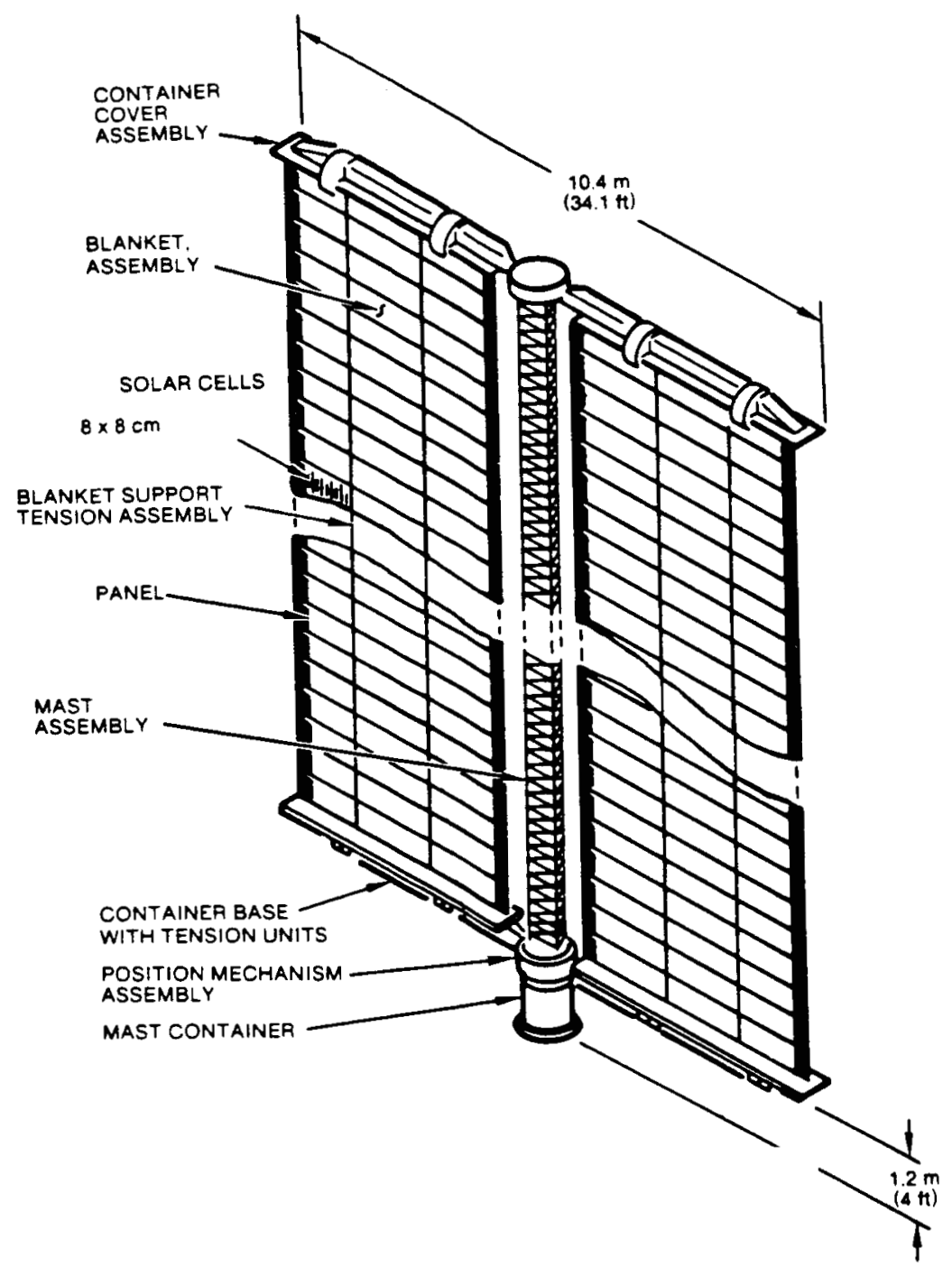

FIGURE 1. - TWO-BLANKET FLEXIBLE SOLAR ARRAY.

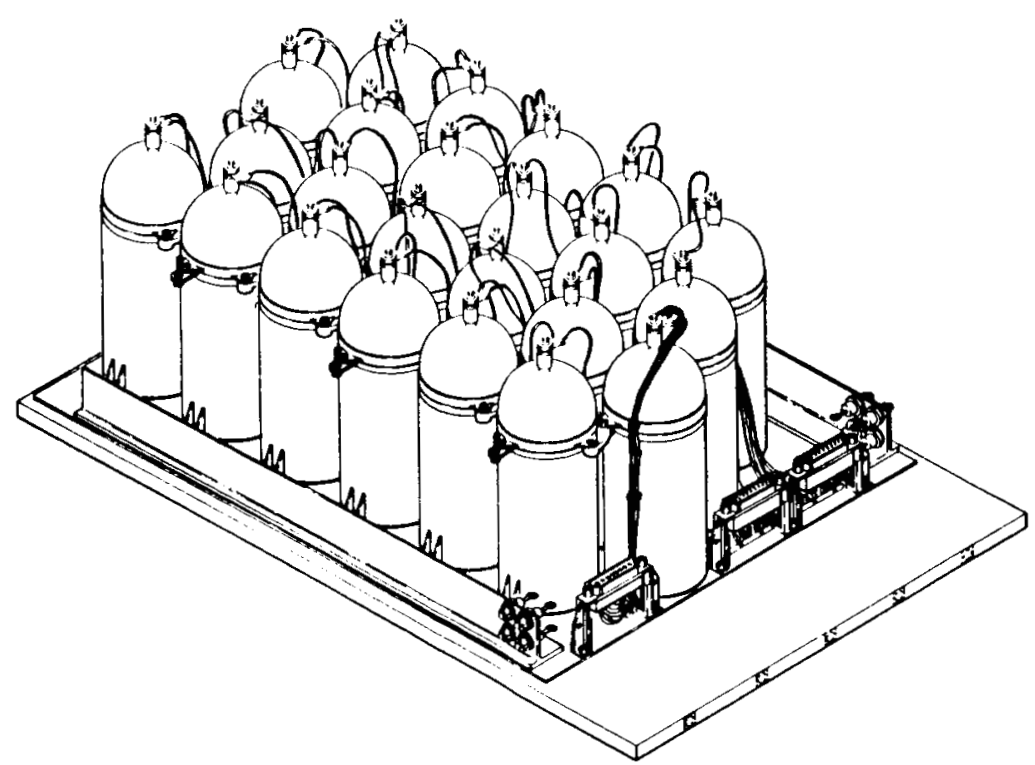

FiguRE 2. - REPRESENTATIVE $\mathrm{N}_{\mathrm{I}}-\mathrm{H}_{2}$ BATTERY PACK. 


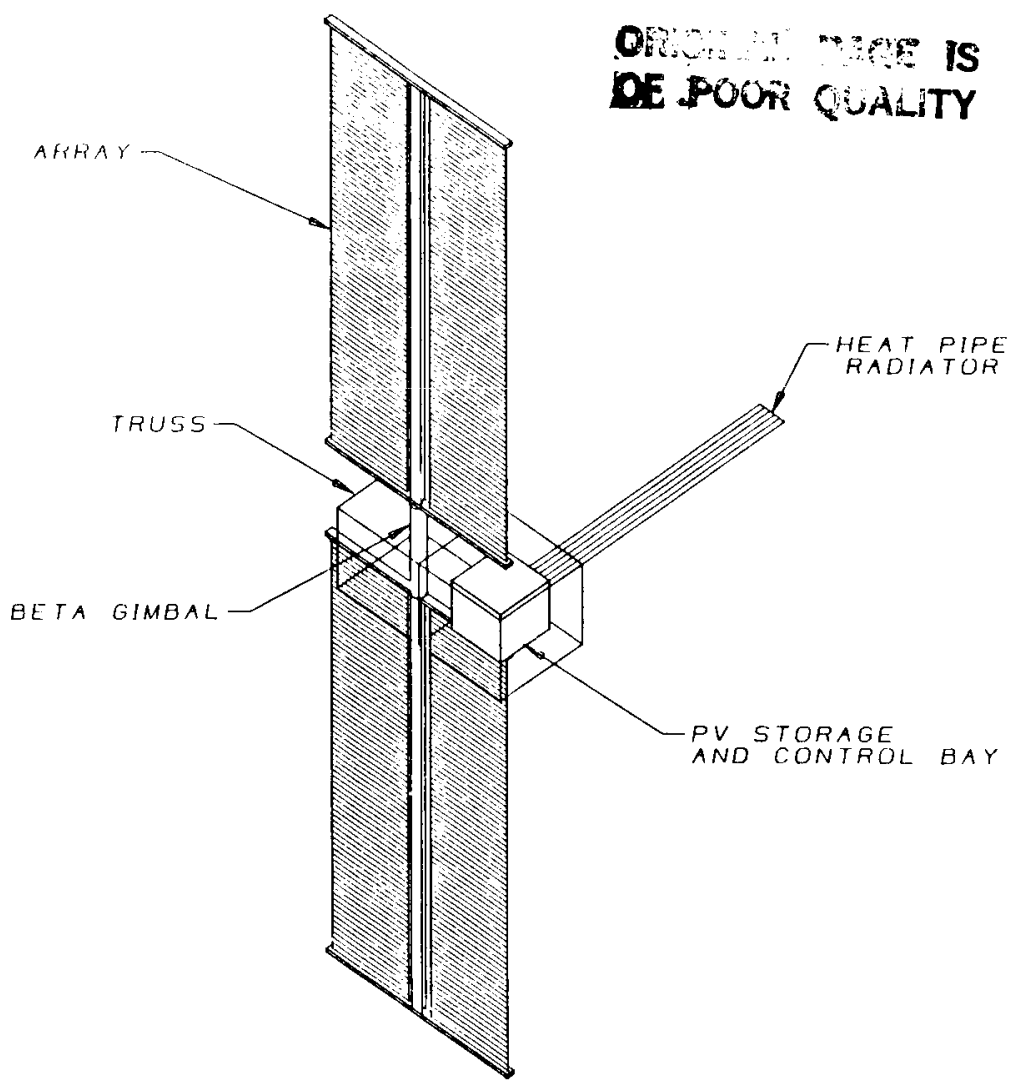

FIGURE 3. - PHOTOVOLTAIC POWER MODULE CONFIGURATION.

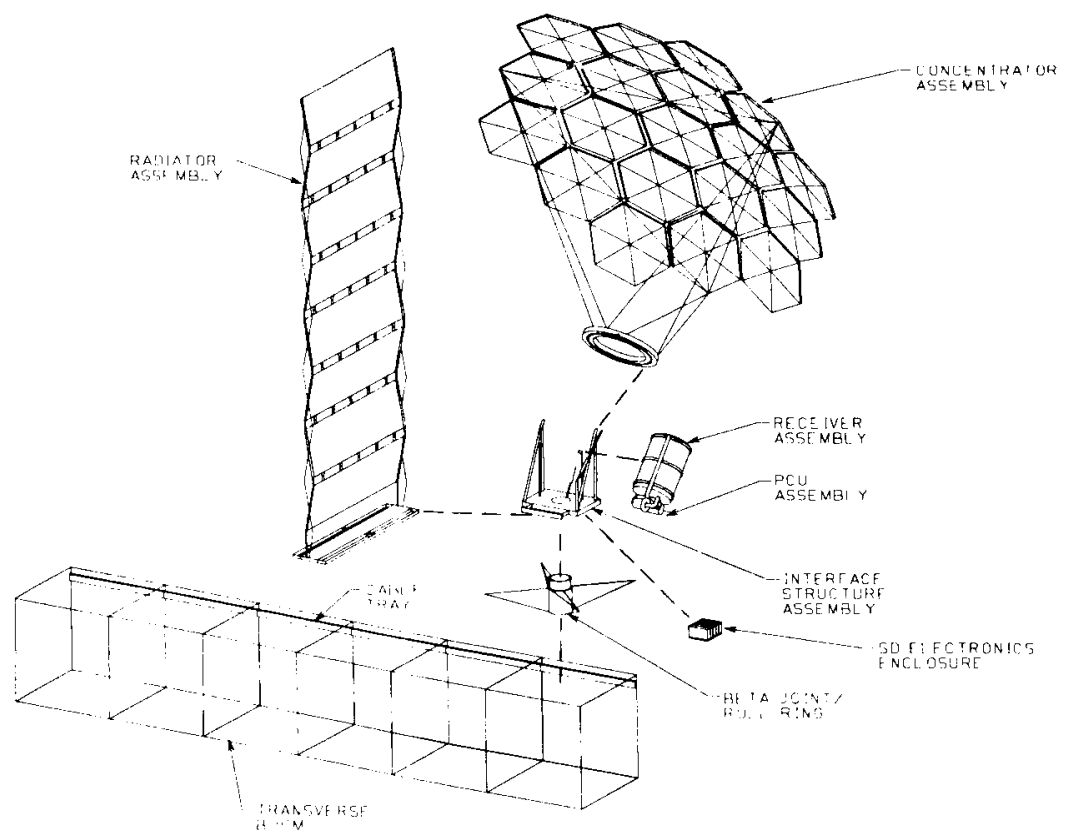

FIGURE 4. - EXPLODED VIEW OF A SOLAR DYNAMIC MODULE (CBC). 


\section{ONG VAL DOAE IS \\ OF POOR QUALITY}

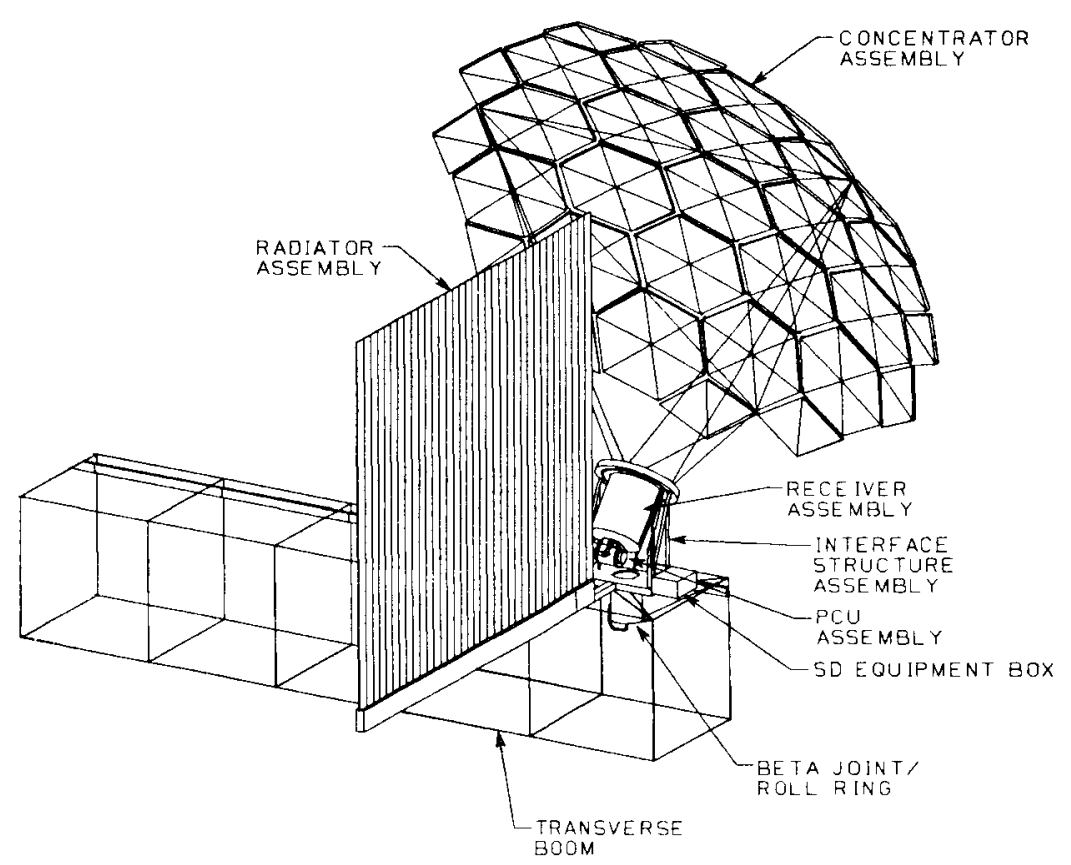

FIGURE 5. - ASSEMBLED SOLAR DYNAMIC MODULE (ORC). 


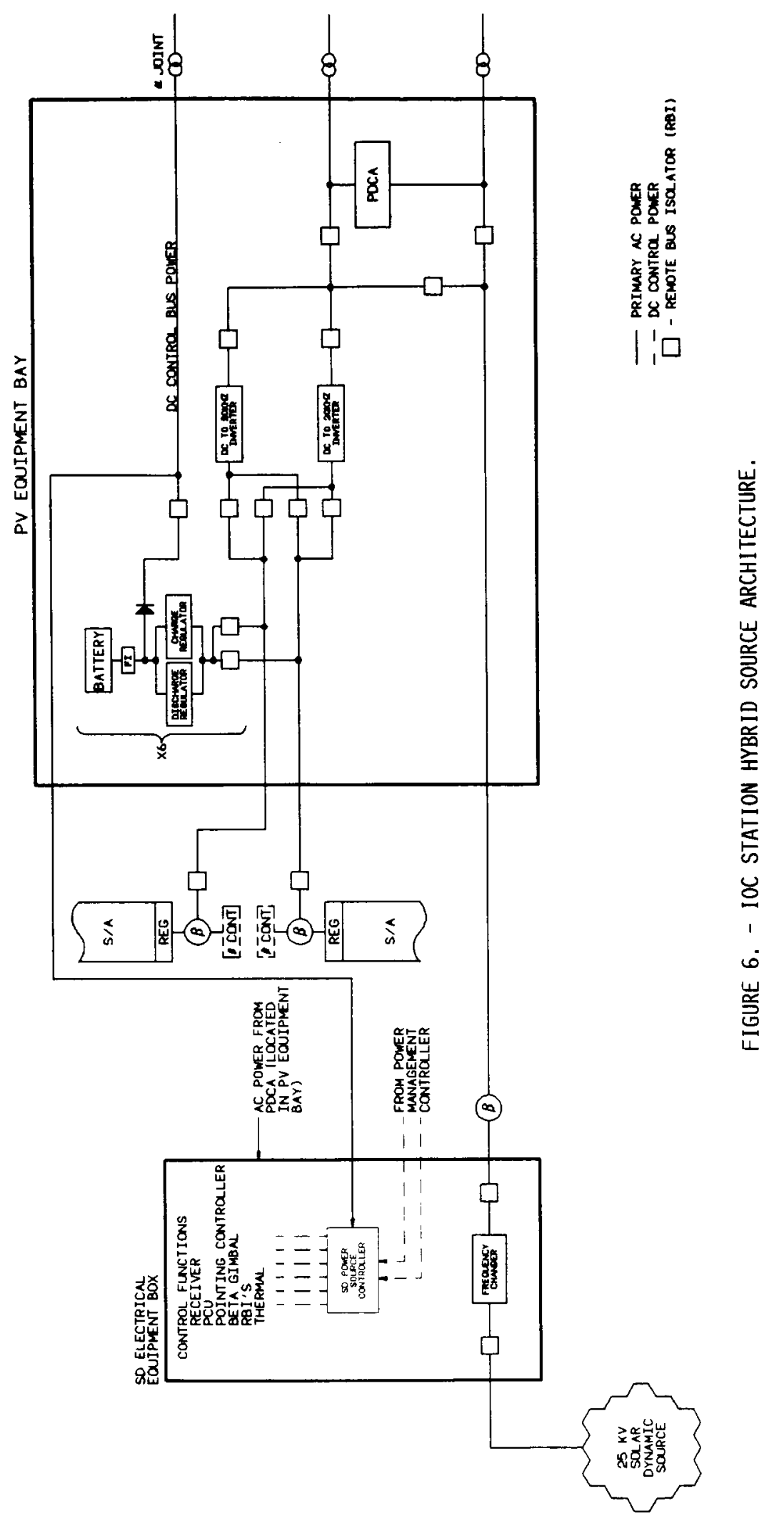




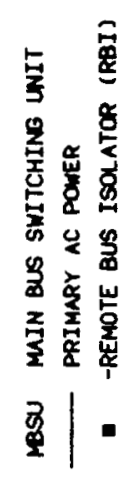

.

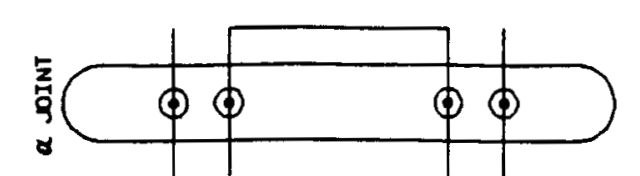

C.T. OP IS OF POOR QUALTY

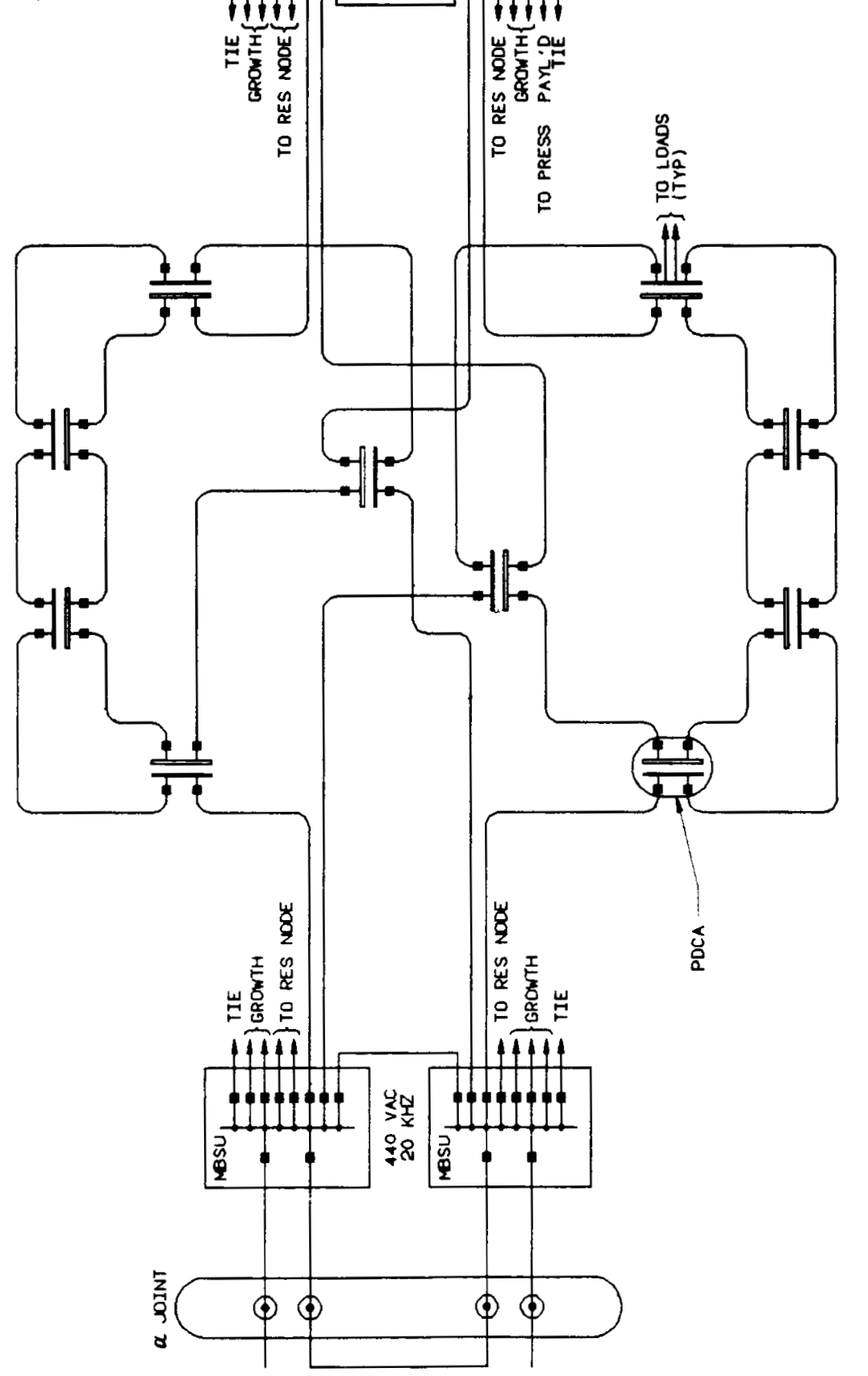

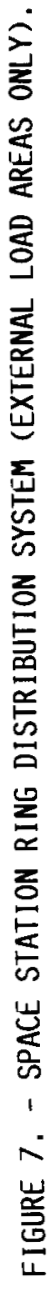
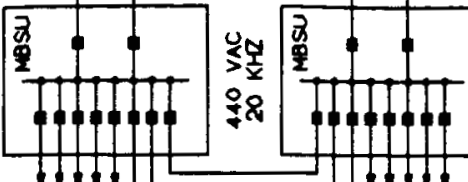

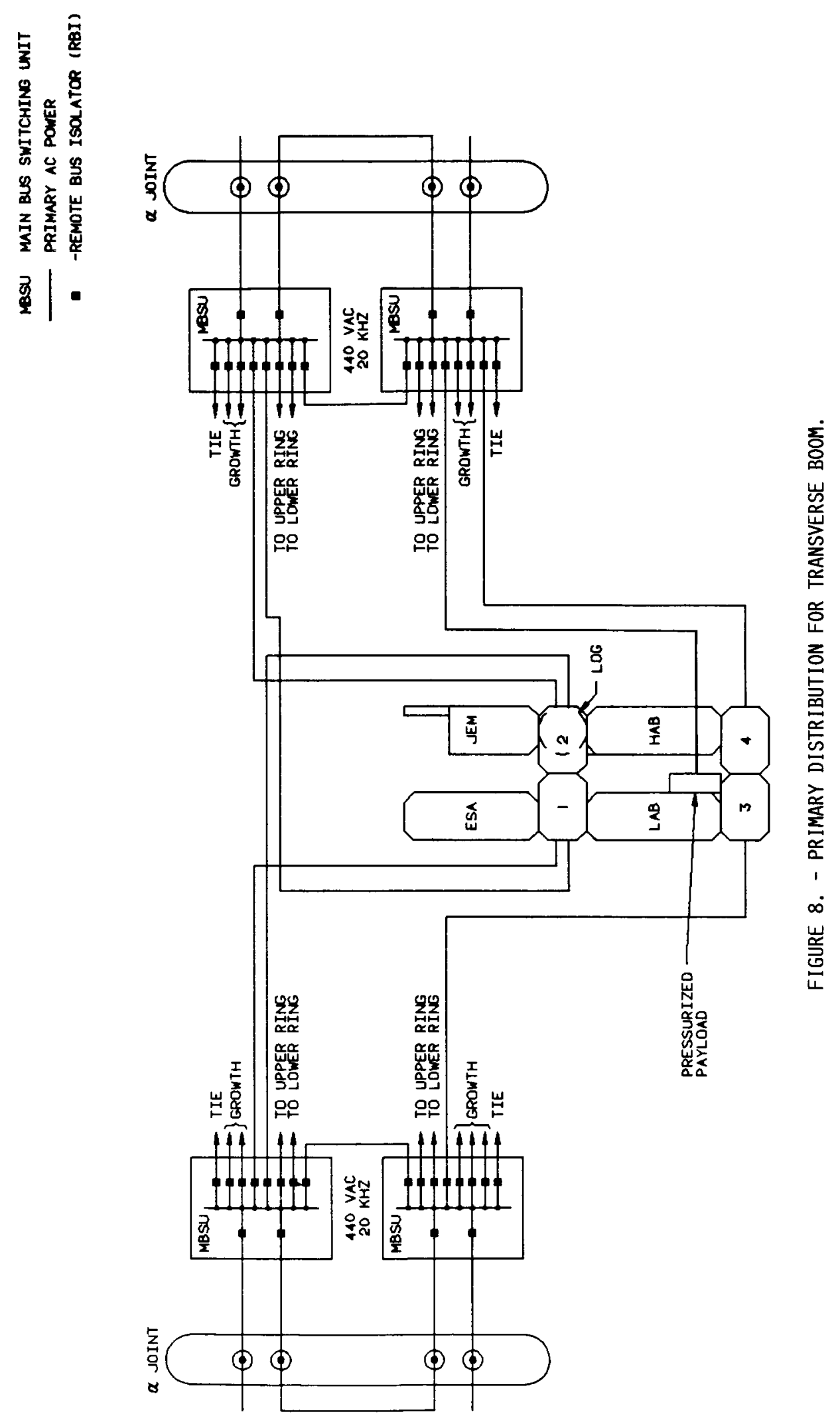


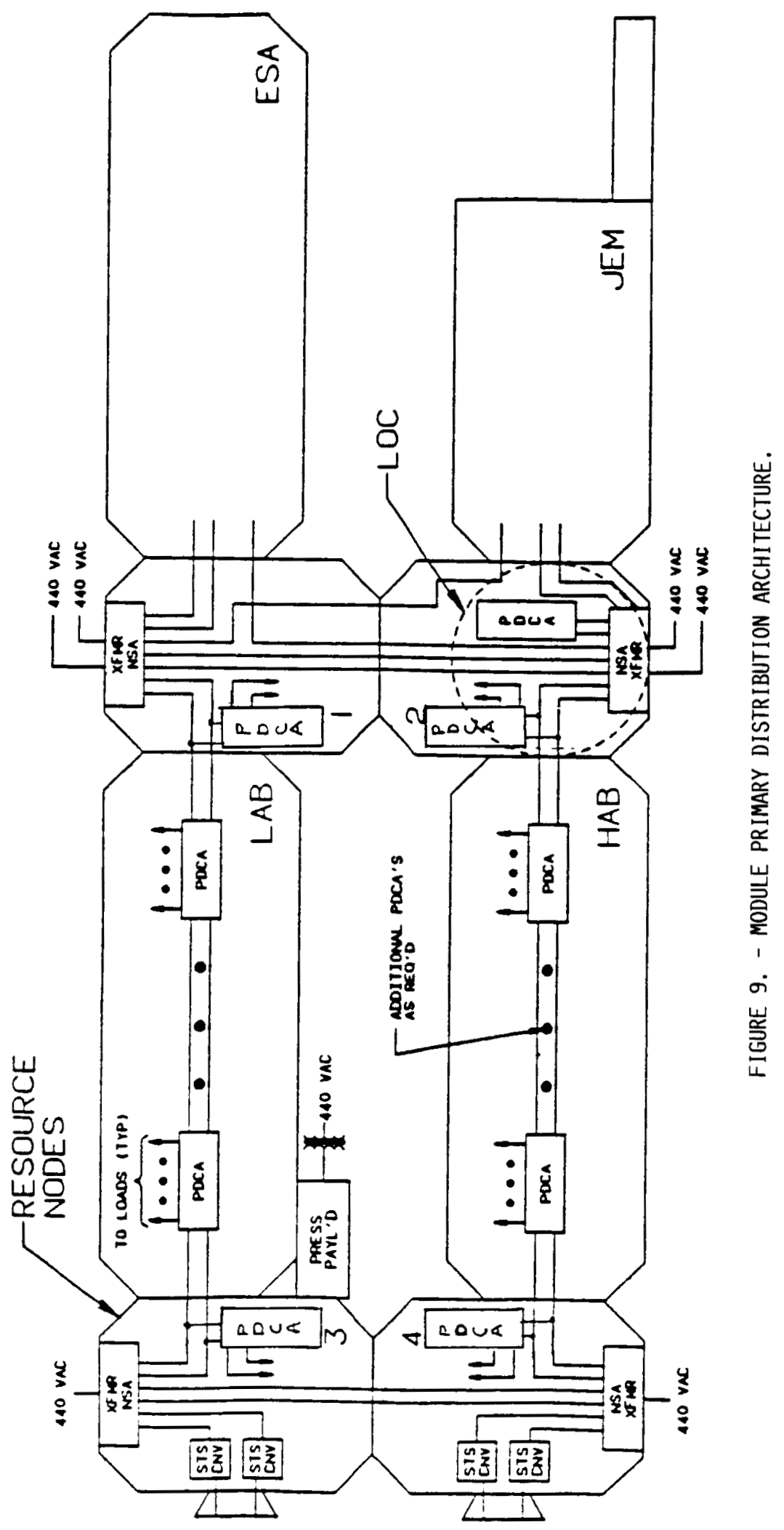




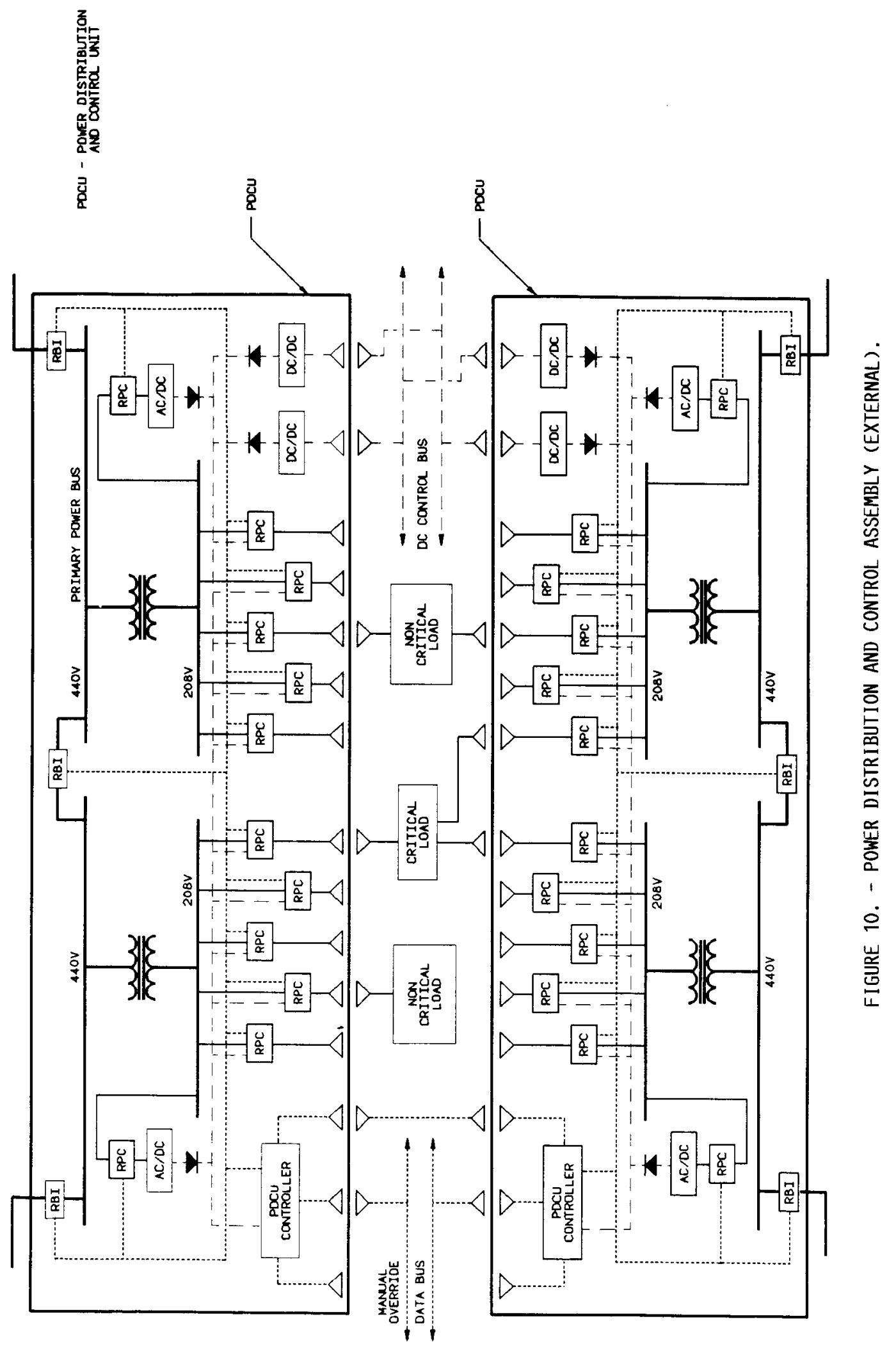






Figure 11. - POWER MANAGEMENT dATA BUS ARCHITECTURE. 


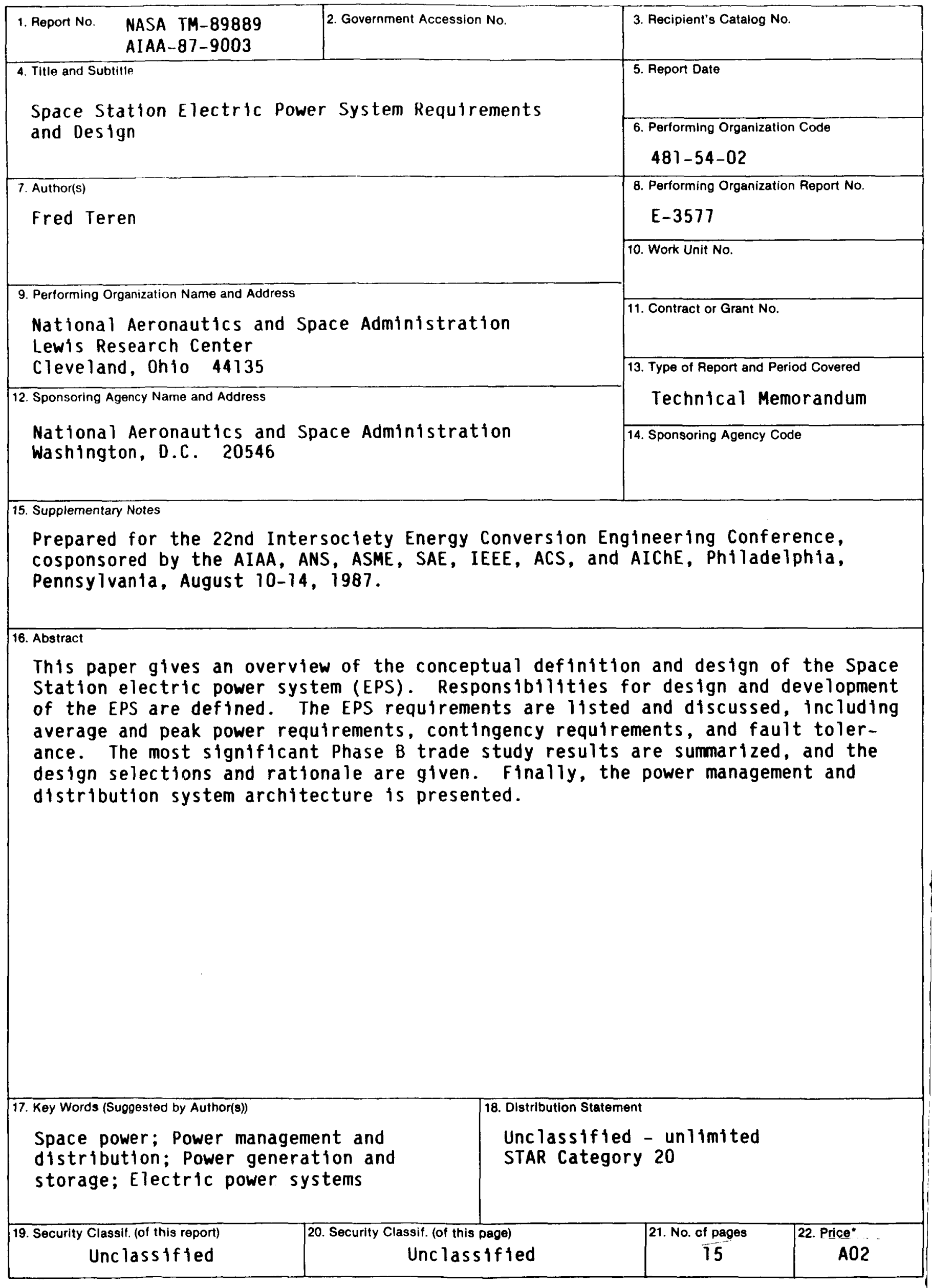

"For sale by the National Technical Information Service, Springfield, Virginia 22161 